\title{
A semidemand feeding protocol reduced time to full oral feeding in healthy preterm infants
}

\author{
McCain GC, Gartside PS, Greenberg JM, et al. A feeding protocol for healthy preterm infants that shortens time to oral \\ feeding.J Pediatr 2001 Sep;139:374-9.

\section{QUESTION: In healthy preterm infants, is a semidemand feeding protocol more effective than the standard practice of scheduled feedings for reducing the time to attain full oral feeding and maintaining a satisfactory weight gain?}

Design

Randomised (unclear allocation concealment), unblinded controlled trial with \{follow up to attainment of full oral feeding\}*.

Setting

2 neonatal intensive care units in Cincinnati, Ohio, USA.

Participants

89 preterm infants who were 32 to $\leqslant 34$ weeks postconceptional age and appropriate for gestational age. Infants with congenital anomalies, gastrointestinal conditions, neurological diagnoses, or grade III/IV intracranial haemorrhage were excluded. 81 infants (91\%) completed the study (mean postconceptional age at study entry 32 wks, $53 \%$ boys).

\section{Intervention}

44 infants were allocated to a semidemand feeding protocol. 10 minutes of non-nutritive sucking (NNS) were

\section{COMMENTARY}

The study by McCain $e t a l$ is one of 3 randomised controlled trials that have examined the effectiveness of demand related versus scheduled feeding regimens in preterm infants. McCain et al overcome the limitations of the 2 earlier trials ${ }^{12}$ by controlling for weight at study entry and caloric requirements ( $\mathrm{kcal} / \mathrm{kg}$ of body weight per day), and by clearly describing the medical and demographic characteristics of the 2 study groups. In addition, McCain et al extend the experimental feeding protocols used in previous studies by using not only a semi demand feeding method contingent on infant behaviour, but also including NNS as part of the protocol. Finally, McCain et al used a sample size that ensured sufficient power to detect significant differences between groups, which was not possible in previous studies.

Study limitations should be considered. It is unclear whether there was adequate concealment of sample allocation during randomisation or if clinicians were blinded to study outcomes. There is also lack of clarity about who fed the infants: nurses, parents, or both. Infants in the study were healthy, bottle fed preterm infants, which may limit the generalisability of the results to less healthy or breast fed preterm infants.

The results suggest a safe method for assisting healthy preterm infants to achieve full oral feeding in a timely manner. Inclusion of breast fed infants would have enhanced the clinical relevance of the study given the increasing number of parents who choose to breast feed their healthy preterm infants and the current emphasis on breast feeding in neonatal centres. More discussion on the efficacy of including NNS as an intervention within the feeding protocol would have been helpful. Attaining full oral feeding is an important discharge criterion for healthy preterm infants. Measuring the effect of the semi demand feeding protocol on length of hospital stay would have helped to determine whether this protocol was associated with cost savings.

Brenda Stade, RN, MScN Clinical Nurse Specialist, Neonatal Nurse Practitioner, Doctoral Candidate Catherine Bishop, RN, BScN

Clinical Nurse Educator St. Michael's Hospital

Toronto, Ontario, Canada

1 Collinge JM, Bradley K, Perks C, et al. Demand vs scheduled feedings for premature infants. JOGN Nurs 1982;11:362-7.

2 Saunders RB, Friedman CB, Stramoski PR. Feeding preterm infants. Schedule or demand? J Obstet Gynecol Neonatal Nurs 1991;20:212-8.

provided every 3 hours, followed up by an assessment of behavioural state (modified Anderson Behavioral State scale). If the infant was judged to be in a state of restlessness or wakefulness (scores $\geqslant 3$ ), an oral feeding was offered. If the infant was in a sleep state, he was allowed to sleep for another 30 minutes and then assessed again; if at the second assessment the infant was still in a sleep state, he was fed by gavage. 45 infants were allocated to the control protocol, which comprised prescribed volumes of oral and/or gavage feedings at 3 hour intervals, with feeding time restricted to $\leqslant 30$ minutes per feeding. Infants were started at 1 oral feeding per 24 hours, and advanced daily according to the protocol depending on weight gain, residual volumes $\leqslant 10 \%$ before each feeding, and absence of apnoea or bradycardia during oral feeding. In both groups, infants who did not ingest the prescribed nutrient volume orally were given the remainder by gavage.

When an infant attained full oral feeding (ie, ingested all nutrient volumes in a $24 \mathrm{~h}$ period without any gavage), the nasogastric tube was removed and the infant continued his or her study protocol for an additional 48 hours with all feedings offered orally. Infants in the semidemand group continued with behavioural assessments every 3 hours, but the time between feedings increased from 3.5 hours to up to 5 hours if an infant was sleeping. Infants in the control group continued to be fed prescribed volumes on a 3 hour schedule to meet $105-130 \mathrm{kcal} / \mathrm{kg} /$ day.

\section{Main outcome measures}

Days to full oral feeding and weight gain.

\section{Main results}

Infants who were allocated to a semidemand protocol had a shorter time to full oral feeding (mean 5 d) than infants allocated to the control group (mean $10 \mathrm{~d}$ ) (difference between means $5 \mathrm{~d}$, $\{95 \%$ CI 3.4 to 6.6$\} \dagger)$. The groups did not differ for weight gain: during the gavage to oral feeding phase, the semidemand group gained a mean of $23.5 \mathrm{~g} /$ day and the control group gained a mean of $26.3 \mathrm{~g} /$ day, and during the full oral phase, the semidemand group gained a mean of $31.9 \mathrm{~g} /$ day and the control group gained a mean of $33.5 \mathrm{~g}$ /day.

\section{Conclusions}

Healthy preterm infants who were fed on a semidemand schedule contingent on behavioural state achieved full oral feeding 5 days sooner than infants who were given scheduled feedings. Infants in both groups had satisfactory weight gains.

*Information provided by author.

†Calculated from data in article. 